\title{
Preliminary results of modified interstitial MIAMI brachytherapy applicator for treatment of upper and apical vaginal tumors
}

\author{
Payal Patel, MD!, Christopher Deufel, PhD², Michael Haddock, MD², Ivy Petersen, MD² \\ 'Mayo Clinic Alix School of Medicine, Rochester, MN, USA, ²Department of Radiation Oncology, Mayo Clinic, Rochester, MN, USA
}

\begin{abstract}
Purpose: Intracavitary vaginal brachytherapy (VBT) cylinders are limited in treating upper/apical vaginal disease due to the distance between the target and radiation source positions. Interstitial brachytherapy devices directly expose the vaginal mucosa to radiation sources, increasing morbidity. To target apical disease while limiting excessive treatment to the vaginal mucosa and organs at risk, we modified the commercially available multichannel MIAMI applicator, allowing the direct extension of needles into the apex with the protection of cylinder.

Material and methods: The device has one central plastic core with six peripheral channels. The modified device permits titanium needles to surpass the apical surface into vaginal tissue. A retrospective analysis on thirteen patients treated with this device was conducted. Patient demographics, gross tumor volume (GTV)/clinical target volume (CTV), initial diagnosis and management, toxicity data, and $\mathrm{EQD}_{2}$ data for the bladder and rectum were obtained.

Results: There were ten patients with vaginal recurrences and three with primary vaginal/cervical cancers. Mean dosage of VBT treatment was 25.5 Gy in 3-5 fractions. Mean dosage of external beam radiation therapy (EBRT) treatment was $44 \mathrm{~Gy}$. Common acute toxicities included diarrhea, fatigue, cystitis, and nausea. Common chronic toxicities were pelvic pain, vaginal stenosis, and skin telangiectasia. Mean $\mathrm{EQD}_{2}$ dose for bladder and rectum were $72.3 \mathrm{~Gy}$ and 62.3 Gy, respectively. Ten patients had no evidence of relapse, two suffered from distant metastases, and one patient with stage IIIA cervical adenocarcinoma had loco-regional recurrence seventeen months after radiation treatment.

Conclusions: Our data suggests that the custom applicator is associated with robust dosimetric coverage, good loco-regional control, acceptable toxicity, and reduced tissue trauma. This device allows treatment of apically located vaginal tumors without significant damage to the vaginal vault and organs at risk. Additionally, it provides the flexibility to treat multiple patients with variable vaginal diameters and sizes/depths of apical tumors using a single device.

J Contemp Brachytherapy 2020; 12, 6: 562-571 DOI: https://doi.org/10.5114/jcb.2020.101689
\end{abstract}

Key words: vaginal brachytherapy, multichannel, endometrial cancer, vaginal cuff, apical tumor.

\section{Purpose}

Cancers involving vagina, with primary vaginal and cervical tumors as well as recurrent endometrial and cervical cancers warrant consideration of combination therapy with external beam radiation therapy (EBRT) and vaginal brachytherapy (VBT) $[1,2,3,4]$. Selection of the optimal VBT device requires careful review of the extent and location of vaginal disease [5].

Primary cervical cancers with minimal vaginal extension can be treated with a variety of intracavitary applicators. When a disease extends to the lower vagina, cylinders with a central tandem are typically used, allowing a uniform circumferential dose to the vaginal surface that can encompass a larger volume at the level of cervix [6]. In primary vaginal cancers or recurrent tumors involving the vagina with limited lateral and apical extension, single channel vaginal cylinders (SCVCs) are often utilized, which can treat a disease up to 5-7 $\mathrm{mm}$ in lateral depth with a uniform circumferential dose distribution [7]. Commercially available multi-channel vaginal cylinders (MCVCs) with channels within the confines of the device, allow for greater, asymmetric dosimetric coverage of lateral wall disease [8]. On the other hand, the anisotropic effect of SCVCs and MCVCs limit the ability to deliver significant dose to the vaginal apex. Typically, when there is substantial apical and/or lateral extent of a disease, a perineal interstitial device, such as a Syed or MUPIT, is utilized $[9,10,11]$. However, these applicators have limitations. The small, vaginal obturators for these perineal templates, with needles in direct contact with the vaginal mucosa, deliver a significantly higher dose to the mucosal tissues, which could damage healthy tissues
Address for correspondence: Ivy Petersen, MD, Department of Radiation Oncology, Mayo Clinic, $2001^{\text {st }}$ St. SW, Rochester, MN, USA, phone: +1 (507) 284-2669, fax: +1 (507) 284-0079,

a-mail: Petersen.Ivy@mayo.edu
Received: 18.05 .2020

Accepted: 12.08 .2020

Published: 16.12.2020 
[12]. Their usage is also associated with increased procedural morbidity, hospitalization time, invasion of normal tissue, and requirement of regional or general anesthesia $[7,12]$.

It has been recently recognized that the use of additional needles for primary cervix cancers improves the therapeutic ratio for larger tumors [13]. In vaginal lesions, where the disease is confined to the superficial vagina but has larger volume disease in the cervix or vaginal apex, the use of an interstitial device with vaginal mucosa protection would have advantages over SCVCs, MCVCs, and perineal interstitial templates by maximizing the dose to target tissues in the apex and minimizing the dose to healthy vaginal mucosa and organs at risk (OARs) [11].

To target apically located lesions while leveraging the benefits of MCVCs, our institution modified the commercially available MIAMI multichannel applicator (Mick Radio Nuclear Instruments, New York, NY, USA), which permit the needles to extend beyond the cuff of the applicator to be placed directly into the tissue in the vaginal cuff. Herein, this applicator will be referred to as the interstitial MIAMI applicator. Since the MIAMI cylinder fully encompasses the needles' circumferences, there is no direct trauma to the lateral vaginal mucosa during needle placement, unlike the Syed or MUPIT templates. Theoretically, the device would allow for asymmetric loading apically and laterally, and permit for optimum conformity of the dose to the tumor. In this paper, the early results of using this device on patients treated at our institution through evaluation of acute/chronic toxicities, dosages to OARs, tumor control, and recurrence

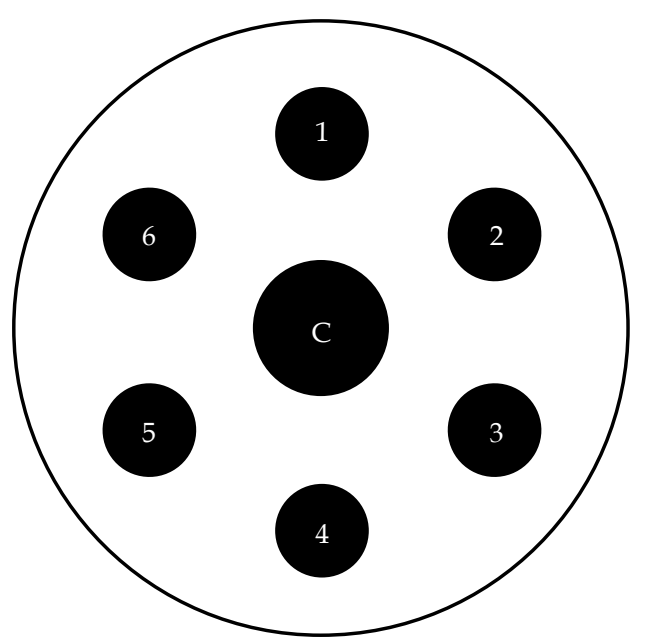

Fig. 1. Cross-sectional graphical representation of multichannel applicator

rates were evaluated, followed by a comparison of this device with other commercially available brachytherapy appliances.

\section{Material and methods}

The unmodified computed tomography (CT)-compatible MIAMI multichannel applicator consists of a central cylindrical plastic core, with one central tandem channel and six peripheral channels, presented in Figure 1. The applicator is additionally supplied with one straight

\section{B}

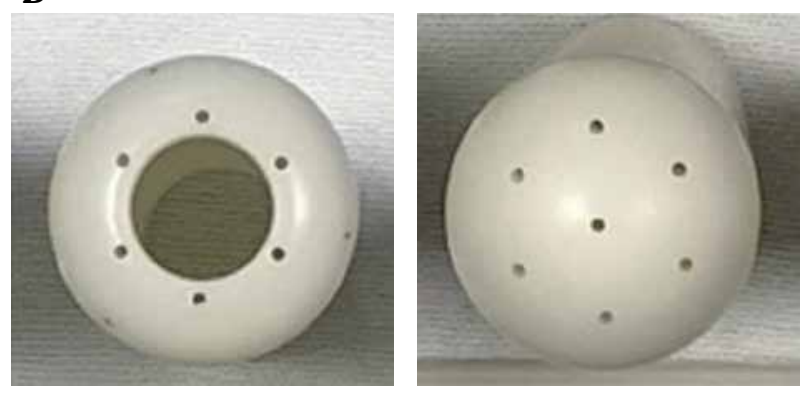

C
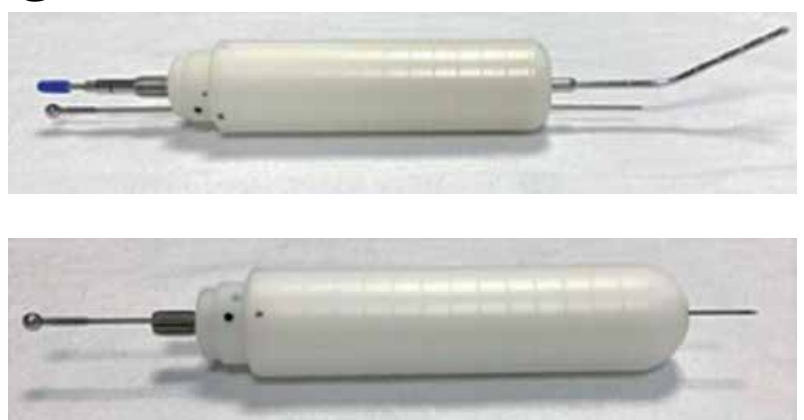

Fig. 2. Interstitial MIAMI applicator set. A) The applicator set consists of an applicator core, cylinder sleeves (diameters of 3.0, 3.5, $4.0 \mathrm{~cm}$ ) to accommodate a central tandem or needle, ring clamps, straight and 45-degree tandems, and $17 \mathrm{~g}$ needles.

B) Top view of the applicator sleeves. Holes were drilled through the apex of the sleeves to allow for penetration of $17 \mathrm{~g}$ needles.

C) A 17 g needle is shown exiting apically through the sleeves with a tandem (top image) and with a needle (bottom image) 
tandem, one $30^{\circ}$ uterine tandem, and three outer plastic shells of 3.0,3.5, and $4.0 \mathrm{~cm}$ in diameters. Multiple channels enable an asymmetric dose distribution through asymmetric loading of radiation source dwells. We modified the applicator using a $1 / 16^{\prime \prime} \times 12^{\prime \prime}$ drill bit supplied by Bosch (Appendix A) to extend the length of original peripheral and central channels, as shown in Figure 2. This permitted $17 \mathrm{~g}$ titanium needles, uniformly spaced $1 \mathrm{~cm}$ apart, to be inserted into each channel and pass beyond the cuff of the outer shell to reach the apically located tumors. Ring clamps were constructed by the Mayo Clinic Division of Engineering that secured the cylinders to the patient's table.

The detailed technique of treatment with the MIAMI applicator is available in published literature [14]. Each patient had positron emission tomography (PET)/CT and magnetic resonance imaging (MRI) scans to determine the size, spread, and extent of the disease. Bladder filling was done before treatment planning and delivery of radiation to protect the small bowel. Treatment plans were optimized using a combination of EBRT, VBT, interstitial freehand needles, and, when appropriate, concurrent cisplatin-based chemotherapy. Pre-implant MRI imaging often employed an MRI compatible cylinder in the vagina, matching the size of the MIAMI applicator. For each patient, one of the three plastic sleeves was selected to best match the vaginal anatomy. Then, CT/MRI and ultrasound imaging were used to place the interstitial MIAMI applicator and needles. For patients without a uterus, the applicator was placed first. For patients with intact cervix/uterus, the tandem was placed initially, and the cylinder was inserted over the tandem. Next, pre-selected needles were advanced beyond the end of the device into the vaginal apex to desired lengths. Free-hand needles were then placed, often with the assistance of rectal ultrasound for lateral and posterior positions. The peripheral needles were then locked in place using a slight rotation of the outer sleeve of the cylinder, with respect to the plastic core and similar to commercial brachytherapy templates (e.g., Mick Radio-Nuclear prostate template), whereby the needles pass through a plate and counter plate that are physically offset from each other to prevent the needles from moving.

Once the applicator and needles were secured, 3D CT planning was repeated and data were exported to the treatment planning system (Eclipse, Brachytherapy Planning v 15.1, Varian Inc., Palo Alto, CA, USA). CT images were fused with pre-implant MRI images to identify target volumes. The high-risk clinical target volume (CTV) and critical organs (small bowel, large bowel, rectum, and bladder) were contoured by the radiation oncologist. The needle locations were reconstructed from the CT images. The needle lumens and tips were easily identifiable due to the relatively high density of titanium needles with respect to the surrounding cylinder and tissues. Inverse optimization with a TG-43 dose calculation was used to meet the dosimetric objectives, including optimizing the high-risk CTV $\mathrm{D}_{90}$ to receive more than $90 \%$ of prescription, restricting vaginal mucosal dose to less than $200 \%$ of prescription outside areas of gross disease, and restricting dose to OARs based on the American Brachytherapy Society (ABS) guidelines [15]. Subsequently, a pre-treatment quality assurance was completed, including standard checks for brachytherapy procedures and, specifically for the modified MIAMI, confirmation that the needles were in the desired location by comparing the measurement of the needle lengths external to the device with their values at the time of placement and imaging. Lastly, the patient was treated using a VariSource iX afterloader containing a VS2000 model ${ }^{192}$ Ir source.

With the Institutional Review Board approval (IRB number 17-011056), electronic medical records of thirteen patients treated with the interstitial MIAMI applicator between December 2014 and May 2020 were reviewed. Patients received follow-up examinations approximately every 3-4 months for the first 2 years, and 6-12 months in the following 3 years. Imaging was repeated at the discretion of the physician. Toxicity data (categorized as pos-
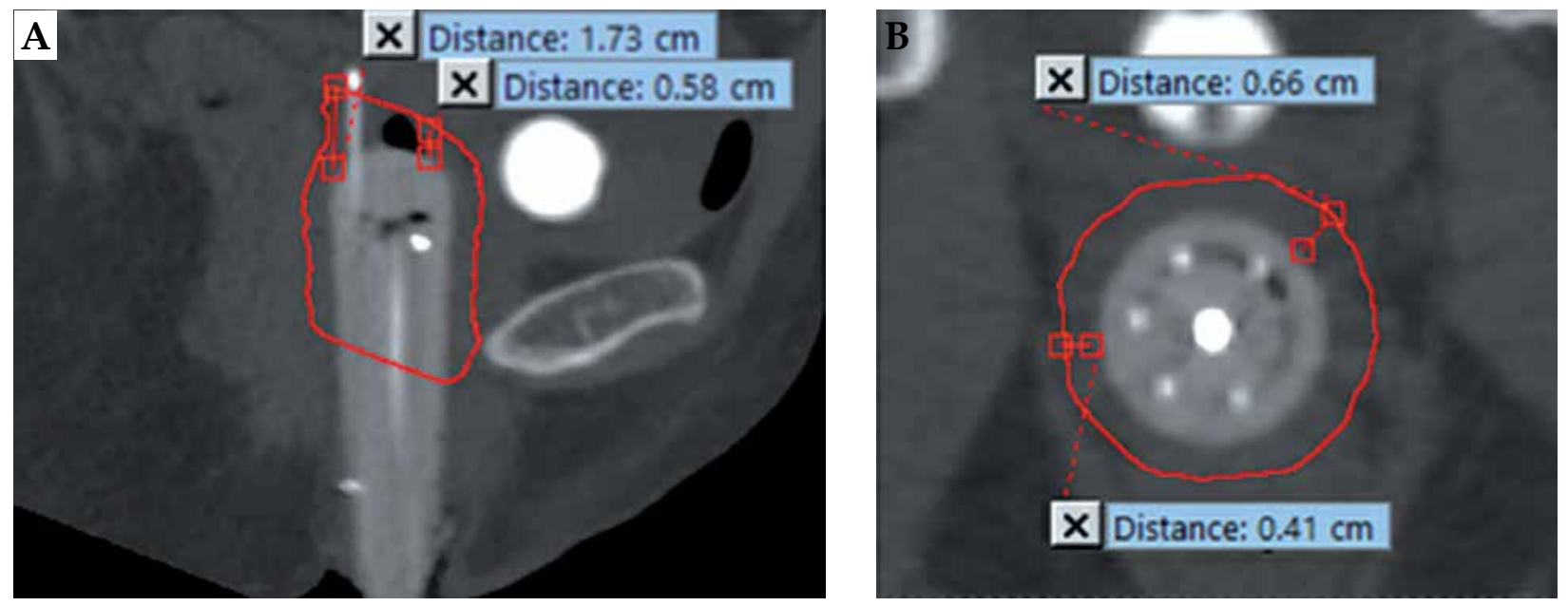

Fig. 3. Measurement of high-risk clinical target volume (HR-CTV) tumor dimensions outlined in red. The sagittal view (A) showing measurement of maximum $(1.73 \mathrm{~cm})$ and minimum $(0.58 \mathrm{~cm})$ distance from the apex of cylinder to the HR-CTV, and the axial view $(\mathbf{B})$ showing measurement of maximum $(0.66 \mathrm{~cm})$ and minimum $(0.41 \mathrm{~cm})$ distance laterally from the cylinder to the HR-CTV 
sibly, probably, or definitively attributed to radiation), patient reported outcomes, medical history, and physical examination were recorded. Acute (less than 3 months) and chronic (greater than 3 months) toxicity data were collected based on the common terminology criteria for adverse events (CTCAE) 4.0. Patients were educated on possible toxicities and the use of vaginal dilators to reduce the risk of stenosis.

Characteristics obtained from patients' charts included age, oncologic medical and surgical history, pathologic tumor characteristics, and treatment plans of the initial disease and recurrences. Central and peripheral needle depths into apical tissue were measured from CT scans acquired after placement of the applicator, using a measurement ruler tool in the treatment planning system, where the depth equaled the distance between the point where the needle exited the cylinder and the needle tip. In addition, the high-risk CTV dimensions were calculated by measuring the minimum and maximum distance of disease extension from the apex and from the lateral sides of the cylindrical shell, as shown in Figure 3. Dosimetric data including gross tumor volume (GTV)/CTV volumes, dose-volume histogram (DVH) data, CTV $\mathrm{D}_{90} / \mathrm{D}_{100}$ and $\mathrm{D}_{2 \mathrm{cc}}$ for the bladder and rectum were obtained. The $\mathrm{D}_{2 \mathrm{cc}}$ data were converted to total $2 \mathrm{~Gy}$ per fraction equivalent dosages $\left(\mathrm{EQD}_{2}\right)$, using the $\mathrm{ABS}$ high-dose-rate (HDR)

Table 1. Tumor characteristics, tumor location, high-risk clinical target volume CTV (HR-CTV) with apical and lateral dimensions, radiation treatment, and $\mathrm{EQD}_{2} / \mathrm{D}_{90}$ data

\begin{tabular}{|c|c|c|c|c|c|c|c|}
\hline $\begin{array}{l}\text { Diagnosis } \\
\text { (FIGO stage) }\end{array}$ & Location & $\begin{array}{l}\text { HR-CTV } \\
\text { apical } \\
\text { lateral } \\
\text { (min-max } \\
(\mathrm{cm}))\end{array}$ & $\begin{array}{l}\text { EBRT } \\
(G y / f x)\end{array}$ & $\begin{array}{l}\text { VBT } \\
(\mathrm{Gy} / \mathrm{fx})\end{array}$ & $\begin{array}{l}\mathrm{EQD}_{2} \\
\text { tumor (Gy) }\end{array}$ & $\begin{array}{l}D_{90} \\
(G y)\end{array}$ & $\begin{array}{c}\mathrm{EQD}_{2} \\
\text { bladder, } \\
\text { rectum } \\
(\mathrm{Gy})\end{array}$ \\
\hline \multicolumn{8}{|l|}{ Primary tumor } \\
\hline $\begin{array}{l}\text { Vaginal squamous cell } \\
\text { carcinoma (II) }\end{array}$ & $\begin{array}{c}\text { Upper } \\
1 / 2 \text { vagina }\end{array}$ & $\begin{array}{l}0.51-1.19 \\
0.30-0.66\end{array}$ & $45 / 25$ & $20 / 4$ & 69.3 & 69.5 & $\begin{array}{l}62.8 \\
62.7\end{array}$ \\
\hline $\begin{array}{l}\text { Vaginal squamous cell } \\
\text { carcinoma }(I I)^{1}\end{array}$ & Apex & $\begin{array}{l}0.93-2.18 \\
0.22-0.68\end{array}$ & N.A. & $20 / 4$ & N.A. & - & - \\
\hline Cervical adenocarcinoma (IIIA) & $\begin{array}{c}\text { Cervix }+ \\
\text { upper } \\
\text { 1/3 vagina }\end{array}$ & $\begin{array}{c}0.12-6.16 \\
0-0.39\end{array}$ & $42.5 / 25$ & $30 / 5$ & 81.4 & 83.5 & $\begin{array}{l}76.2 \\
64.6\end{array}$ \\
\hline \multicolumn{8}{|l|}{ Recurrence } \\
\hline $\begin{array}{l}\text { Cervical squamous cell carcino- } \\
\text { ma (IB) }\end{array}$ & $\begin{array}{c}\text { Apex }+ \\
\text { upper } \\
\text { 1/3 vagina }\end{array}$ & $\begin{array}{l}0.51-0.84 \\
0.27-0.63\end{array}$ & $50 / 25$ & $30 / 5$ & 90.0 & 91.7 & $\begin{array}{l}82.7 \\
74.8\end{array}$ \\
\hline $\begin{array}{l}\text { Endometrial adenocarcinoma } \\
\text { (IB) }\end{array}$ & Apex & $\begin{array}{l}0.62-2.35 \\
0.02-0.14\end{array}$ & $50 / 25$ & $24 / 4$ & 82.0 & 85.8 & $\begin{array}{l}81.2 \\
63.2\end{array}$ \\
\hline $\begin{array}{l}\text { Endometrial adenocarcinoma } \\
(\mathrm{IA})^{3}\end{array}$ & Apex & $\begin{array}{l}0.74-4.76 \\
0.01-0.10 \\
\end{array}$ & $45 / 25$ & $25 / 5$ & 75.5 & 82.0 & $\begin{array}{l}70.9 \\
58.0\end{array}$ \\
\hline $\begin{array}{l}\text { Cervical squamous cell carcino- } \\
\text { ma (IB) }\end{array}$ & $\begin{array}{c}\text { Apex }+ \\
\text { upper } \\
\text { 1/3 vagina }\end{array}$ & $\begin{array}{c}0.94-1.41 \\
0-1.47\end{array}$ & $45 / 25$ & $25 / 4$ & 80.0 & 75.2 & $\begin{array}{l}81.7 \\
74.8\end{array}$ \\
\hline $\begin{array}{l}\text { Endometrial adenocarcinoma } \\
\text { (IA) }\end{array}$ & $\begin{array}{c}\text { Apex }+ \\
\text { upper } \\
\text { 1/3 vagina }\end{array}$ & $\begin{array}{l}0.20-0.63 \\
0.25-0.58\end{array}$ & $45 / 25$ & $25 / 5$ & 75.5 & 73.8 & $\begin{array}{l}66.6 \\
58.7\end{array}$ \\
\hline Cervical neoplasia (unknown) (I) & $\begin{array}{l}\text { Upper } \\
1 / 3 \text { vagina }\end{array}$ & $\begin{array}{l}0.12-0.67 \\
0.09-0.47\end{array}$ & None & $35 / 5$ & 49.6 & - & - \\
\hline Endometrial adenocarcinoma (I) & $\begin{array}{c}\text { Apex }+ \\
\text { upper } \\
\text { 1/3 vagina }\end{array}$ & $\begin{array}{c}0.52-5.46 \\
0-0.12\end{array}$ & $45 / 25$ & $30 / 5$ & 84.3 & 95.5 & $\begin{array}{l}88.3 \\
63.0\end{array}$ \\
\hline $\begin{array}{l}\text { Endometrial adenocarcinoma } \\
\text { (IA) }\end{array}$ & Apex & $\begin{array}{l}0.39-0.74 \\
0.14-0.39\end{array}$ & $45 / 25$ & $21 / 3$ & 74.0 & 72.8 & $\begin{array}{l}69.1 \\
56.8\end{array}$ \\
\hline $\begin{array}{l}\text { Endometrial adenocarcinoma } \\
(\text { III) }\end{array}$ & Apex & $\begin{array}{c}0.69-4.41 \\
0\end{array}$ & $30.6 / 17$ & $18 / 3$ & 54.1 & 52.9 & $\begin{array}{l}39.0 \\
36.5\end{array}$ \\
\hline $\begin{array}{l}\text { Endometrial adenocarcinoma } \\
\text { (IA) }\end{array}$ & $\begin{array}{l}\text { Upper } \\
1 / 3 \text { vagina }\end{array}$ & $\begin{array}{c}0.03-1.65 \\
0-0.83\end{array}$ & $45 / 25$ & $28 / 4$ & 83.9 & 81.2 & $\begin{array}{l}76.8 \\
72.8\end{array}$ \\
\hline
\end{tabular}

${ }^{1}$ unknown dosage of EBRT received in 25 fractions at outside institution, ${ }^{2} E B R T 9 \mathrm{~Gy} / 3$ fx for vaginal bleeding received one month before EBRT/VBT, ${ }^{3} V B T 21$ Gy/3 fx for primary tumor received one year before recurrence, ${ }^{4} E B R T 45 \mathrm{~Gy} / 25 \mathrm{fx}$ and VBT $24 \mathrm{~Gy} / 3 \mathrm{fx}$ for primary tumor received two years before recurrence 
radiobiologic dose equivalent worksheets, with $\alpha / \beta$ values of 10 Gy for target and 3 Gy for OARs [16].

\section{Results}

Three patients were treated for primary and ten for recurrences of endometrial, cervical, or vaginal cancers. Treatments details, along with tumor characteristics, radiation treatment, $\mathrm{D}_{90}$ data, and $\mathrm{EQD}_{2}$ data are presented in Table 1 . Median age was 58 years (range, $30-83$ years). Median time between treatment of primary disease and recurrence was 37 months (range, 6-180 months). For patients who were alive, the median follow-up time from the end of VBT treatment to the most recent clinical visit with our department was 15.1 months (range, 1-49 months), and to the most recent evaluation of oncologic disease with any provider was 36 months (range, 1-54 months). The crude rates, at a median of 36 months, for loco-regional control, distant-control, and overall survival were $92 \%$ (12 of 13), 77\% (10 of 13 ), and $92 \%$ (12 of 13), respectively.

In total, 56 brachytherapy procedures were completed. In all cases, the central channel was used with interstitial placement in 47 of the 56 fractions. A tandem was placed when an intact uterus was present or when it was not required for an interstitial needle to cover the tumor. Each of the six peripheral needles locations was used, on average, in 31 of the 56 fractions. For each treatment, a mean of 5.7 needles (range, 2-7) were used, of which a mean of 4.0 needles (range, $0-7$ ) were extended beyond the applicator into the vaginal apex. Figure 4 visually depicts how the rigidity of the cylinder channels allows the controlled extension of the needles into the apical tissue. The mean distance between the apical surface of the applicator and the tip of the extended needles was $3.3 \mathrm{~cm}$ (range, 0.8-6.5 cm). Three patients had interstitial free-hand needles placed around the applicator for the treatment of lateral disease. Eleven patients had EBRT and VBT treatment at our institution. The mean EBRT dose was $44.4 \mathrm{~Gy}$ in 24 fractions. Four patients received a simultaneous integrated boost of 59.4 Gy (range, 56.25$62.50 \mathrm{~Gy}$ ) for lymphadenopathy. The mean dose for VBT was $25.5 \mathrm{~Gy}$ in 3-5 fractions. Three patients had prior radiation treatment to the pelvis, and one received EBRT of unknown dose in 25 fractions at another facility before VBT at our institution. For all patients, the mean $\mathrm{EQD}_{2}$ data was $72.3 \mathrm{~Gy}$ to the bladder and $62.3 \mathrm{~Gy}$ to the rectum with 1 VBT accounting for a mean $\mathrm{EQD}_{2}$ dose of $29.4 \mathrm{~Gy}$ to the bladder and 19.5 Gy to the rectum. Five patients received weekly cisplatin therapy. Procedures were performed with local anesthesia $(n=3)$, conscious sedation $(n=9)$, or epidural anesthesia $(n=1)$. Ten patients presented toxicity data, of whom eight had grade 1-3 acute toxicities and eight had grade 1-3 chronic toxicities (Appendix B). For patients with varying grades of the same toxicity, the highest grade was reported.

One patient with stage IIIA primary endometrial carcinoma was considered surgically inoperable and received only radiation for treatment. The two patients treated for primary vaginal squamous cell carcinoma had hysterectomies for cervical intraepithelial neoplasia (CIN) stage II/III and leiomyomas years prior to development and treatment of oncologic disease. All other patients had hysterectomies for initial disease or disease recurrence. Three patients developed metastatic disease. One patient had metastases to the pancreas and colon at twenty-three months post-treatment. A second patient had pulmonary metastases at six months, and died of disease shortly afterwards. A third patient had pulmonary metastases nine months after completing radiation treatment and evidence of local-regional recurrence seventeen months after completing radiation treatment.

\section{Discussion}

The interstitial MIAMI applicator shows promising results with good local-regional control of disease for selected patient population with large $(>5 \mathrm{~mm})$, vaginal apex disease. The flexible device allow for controlled extension of interstitial needles directly into thick, api-

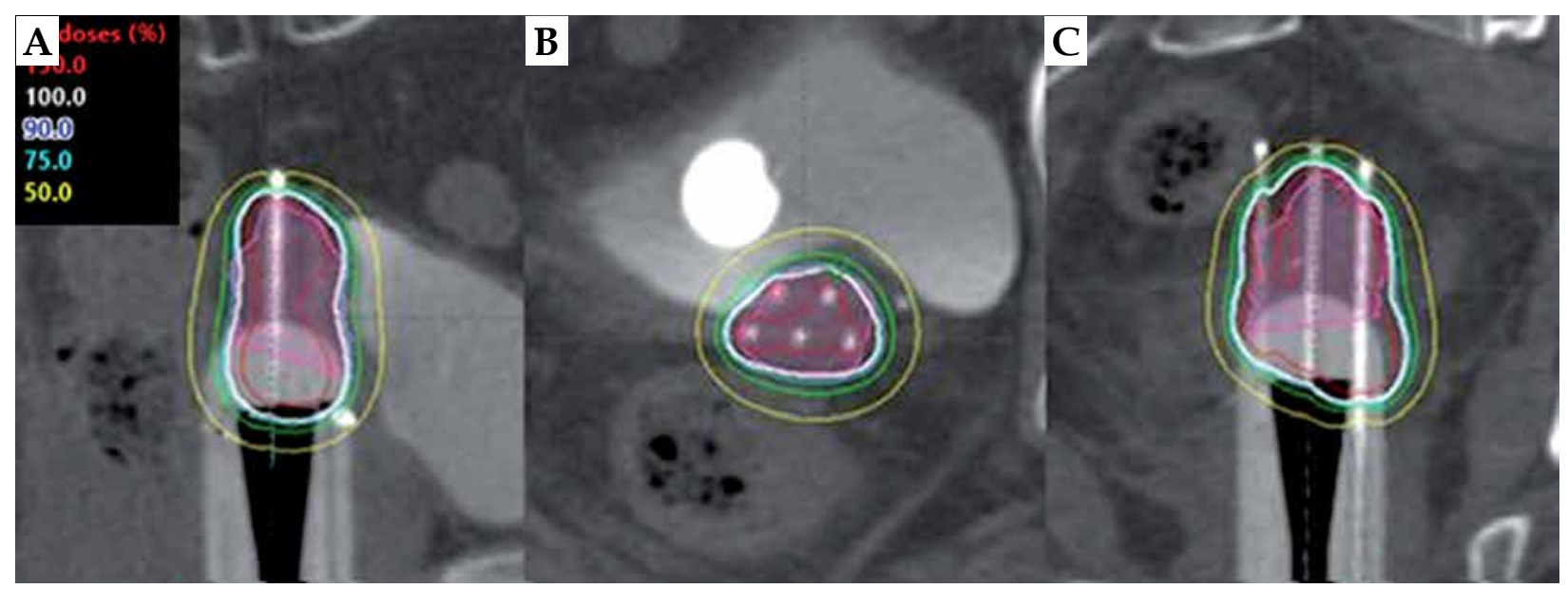

Fig. 4. Sagittal (A), axial (B), and coronal (C) views of a brachytherapy plan using CT-based planning with the modified MIAMI interstitial applicator for apical recurrence of stage IB endometrial adenocarcinoma. Image shows controlled extension of peripheral needles through the channel into the apical tissue. The pink-shaded region represents the high-risk clinical target volume (HR-CTV). The 150\% isodose line is in red, $100 \%$ in white, $90 \%$ in blue, $75 \%$ in green, and $50 \%$ in yellow 
cally located lesions, which are otherwise reserved for free-hand, interstitial brachytherapy (ISBT) or perineal interstitial implants [17]. All patients received adequate treatment coverage while achieving vaginal mucosal limitations, without exceeding the maximal recommended dosage for OARs.

The ABS proposes a dosage of at least 70-85 Gy to recurrent disease, and an $\mathrm{EQD}_{2}$ dose of less than $90 \mathrm{~Gy}$ to the bladder and $70-75$ Gy to the rectum $[2,17,18]$. Here, all patients met the dose constraints to the bladder and rectum, but two patients did not meet the treatment dose guidelines. One patient had a $0.25 \mathrm{~cm}$ endometrial cancer recurrence limited to the apex of the vagina and was treated with VBT alone with an $\mathrm{EQD}_{2}$ dose of $49.6 \mathrm{~Gy}$. The second patient had a prior radiation of unknown dosage for endometrial disease, with evidence of small bowel fixation adjacent to the vaginal cuff, limiting the ability to provide further EBRT safely.

Three patients experienced metastatic disease. Two patients had stage II primary squamous cell carcinoma of the upper vagina, both of whom had local control. The third patient with metastases was treated for primary, stage IIIA adenocarcinoma of the cervix with local recurrence seventeen months after VBT treatment. The patient initially had a $5 \mathrm{~cm}$ cervical mass with multiple PET-avid pelvic and para-aortic nodes, and MRI-positive imaging for invasive, myometrial disease adjacent to the bladder wall. The disease was not amenable to surgical intervention, in part due to sub-urethral vaginal extension. The patient received EBRT of 9 Gy in 3 fractions at an outside institution for marked bleeding one month prior to definitive radiation treatment of 30 Gy in 5 fractions with
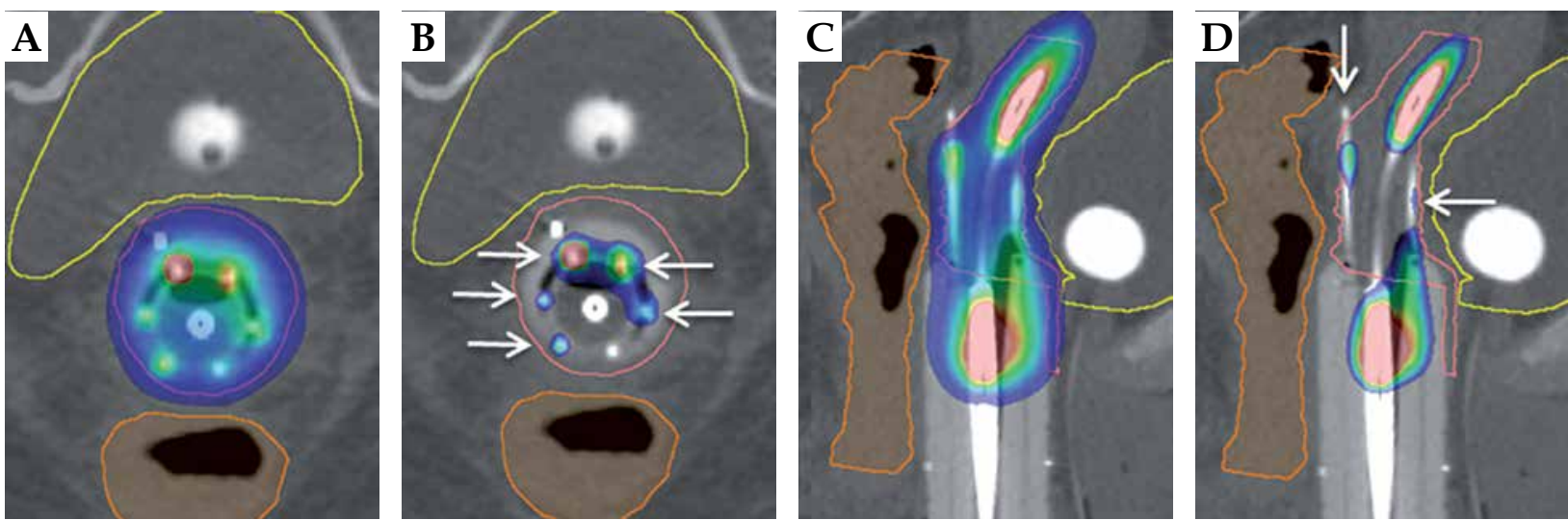

Fig. 5. Intact cervix example: visual representation of benefits of interstitial MIAMI applicator with axial and sagittal views. The pink outline is the high-risk clinical target volume, the yellow outline is the bladder, and the orange outline is the rectum. A) Axial $90 \%$ isodose showing an asymmetric dose distribution avoiding organs at risk. B) Axial $200 \%$ isodose showing interstitial needles (white arrows) contained within the multi-channel cylinder, minimizing high-dose to vaginal wall. C) Sagittal $90 \%$ isodose showing ability to treat the tumor in the cervix as well as the upper vagina, with $>90 \%$ of tumor receiving $90 \%+$ of dose. D) Sagittal 200\% isodose showing controlled placement of needles (white arrows) extending into apical tissue and $200 \%$ isodose away from the vaginal mucosa
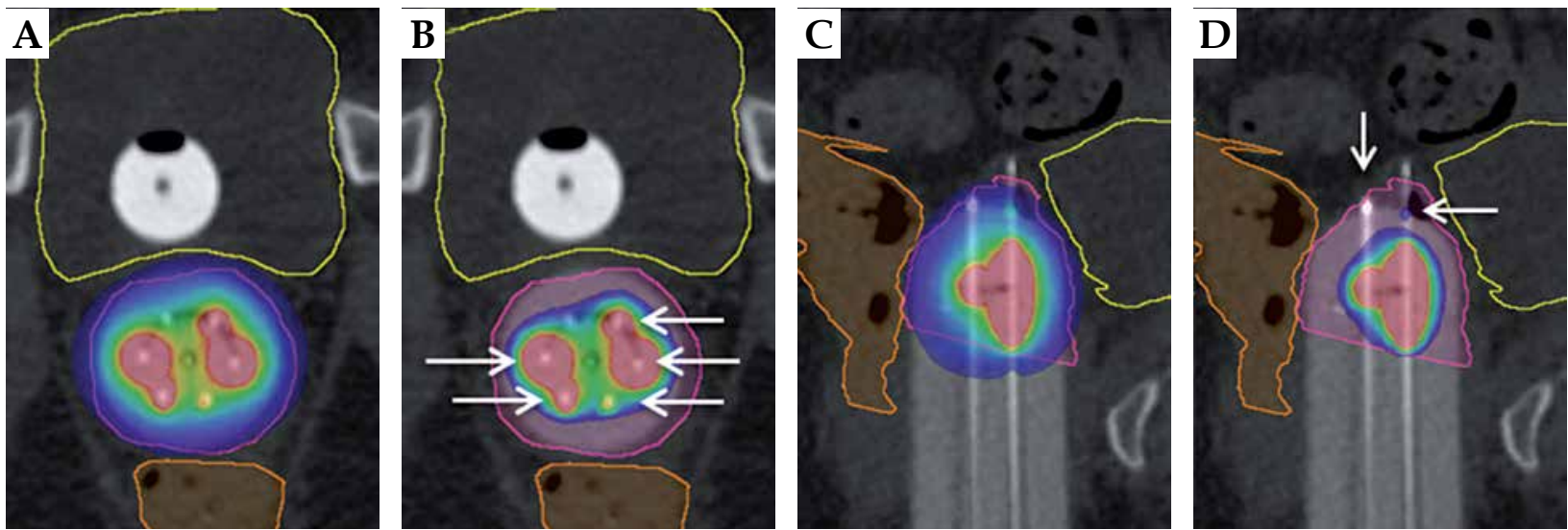

Fig. 6. Apical disease example: visual representation of benefits of interstitial MIAMI applicator with axial and sagittal views. The pink outline is the high-risk clinical target volume, the yellow outline is the bladder, and the orange outline is the rectum. A) Axial 90\% isodose showing asymmetric dose distribution avoiding organs-at-risk. B) Axial 200\% isodose showing interstitial needles (white arrows) contained within the multi-channel cylinder, minimizing high-dose to vaginal wall. C) Sagittal 90\% isodose showing ability to treat the tumor deep in the apex of vagina, with $>90 \%$ of tumor receiving $90 \%+$ of dose. D) Sagittal $200 \%$ isodose showing controlled placement of needles (white arrows) extending into apical tissue and 200\% isodose away from the vaginal mucosa 
the interstitial MIAMI applicator. Six months after VBT, a fistula developed at the level of the lower uterine segment, and eleven months afterwards, imaging confirmed evidence of local recurrence. The patient disease also progressed in the lungs at nine months post-VBT.

Two patients, who received cisplatin-based chemotherapy, experienced grade 3 acute toxicities of nausea and fatigue that resolved in subsequent, follow-up visits. These systemic hematologic and gastrointestinal toxicities most likely occurred from chemotherapy, as toxicities from radiation are typically localized to the treatment region [19]. One patient with grade $3 \mathrm{~A}$ cervical adenocarcinoma developed a fistula complicated with infection requiring surgical intervention. Otherwise, patients had grade 1-2 acute and chronic toxicities, as defined in Appendix B.

The benefits of the interstitial MIAMI applicator, several of which are visually represented in Figures 5 and 6, include the robust treatment of apically located tumors, reduction of excessive radiation to healthy vaginal mucosa and OARs, controlled placement of interstitial needles, choice of appropriate cylindrical shell diameter, ability to deliver asymmetric dose, and reduced need for general anesthesia.

ISBT remains critical to treat large, apically located lesions. Its usage, however, has declined due to technical difficulty, lack of familiarity, time required to perform treatment, desire to avoid procedural morbidity, need for general or epidural anesthesia, and increased overnight hospital stays for peri-operative pain management $[20,21]$. In comparison, the interstitial MIAMI applicator could be more recognizable device, which reduces the use of general anesthetics and length of hospitalizations. Additionally, the modification of the MIAMI applicator can be easily performed on a familiar, existent $\mathrm{MCVC}$, reducing the cost of purchasing a new applicator.

Table 2. Comparison of outcomes for patients treated with interstitial MIAMI applicator to similar patients treated for gynecologic malignancies. These patients received a mix of radiation treatment plans including intracavitary (IC) and/or interstitial (IS) brachytherapy and/or external beam (EBRT). Rates for local control, distant control, overall survival, and data for severe, grade 3 or higher acute and chronic toxicities are reported (when data available) on patients who received brachytherapy. For tumor type, $\mathrm{P}$ - primary, $\mathrm{R}$ - recurrence, V - vaginal, E - endometrial, and C - cervical

\begin{tabular}{|c|c|c|c|c|c|c|c|c|}
\hline $\begin{array}{l}\text { Author name, } \\
\text { date [ref.] }\end{array}$ & $\begin{array}{c}\text { No. of } \\
\text { patients }\end{array}$ & $\begin{array}{l}\text { Tumor } \\
\text { type } \\
\text { treated }\end{array}$ & $\begin{array}{c}\text { Radiation } \\
\text { treatment } \\
\text { (IC, IS, and/or } \\
\text { EBRT) }\end{array}$ & $\begin{array}{l}\text { Time point } \\
\text { of outcome } \\
\text { (months) }\end{array}$ & $\begin{array}{l}\text { Local- } \\
\text { regional } \\
\text { control (\%) }\end{array}$ & $\begin{array}{l}\text { Distant } \\
\text { control } \\
(\%)\end{array}$ & $\begin{array}{c}\text { Overall } \\
\text { survival (\%) }\end{array}$ & $\begin{array}{c}\text { Acute and } \\
\text { late toxicity } \\
\text { data (severe } \\
\text { or grade } 3 \\
\text { or higher) }\end{array}$ \\
\hline $\begin{array}{l}\text { Stock et al., } \\
1992 \text { [27] }\end{array}$ & 38 & PV & $\begin{array}{c}\text { (IC or IC/IS) } \\
\pm \text { ERBT }\end{array}$ & 60 & 44 & N.A. & 50 & N.A. \\
\hline $\begin{array}{l}\text { Chyle et al., } \\
1996 \text { [28] }\end{array}$ & $\begin{array}{c}43 \\
\text { IC only } \\
50 \\
\text { IC + EBRT }\end{array}$ & PV & $\mathrm{IC} \pm \mathrm{EBRT}$ & 120 & $\begin{array}{c}87 \\
\text { IC only } \\
82 \\
\text { IC + EBRT }\end{array}$ & N.A. & $\begin{array}{c}74 \\
\text { IC only } \\
57 \\
\text { IC + EBRT }\end{array}$ & N.A. \\
\hline $\begin{array}{l}\text { Nag et al., } \\
1997 \text { [29] }\end{array}$ & 15 & RE & $\mathrm{IS} \pm \mathrm{EBRT}$ & $\begin{array}{c}55 \\
\text { IS only } \\
36 \\
\text { IS + EBRT } \\
60 \text { All }\end{array}$ & $\begin{array}{c}64.3 \\
\text { IS only } \\
100 \\
\text { IS + EBRT }\end{array}$ & $\begin{array}{l}69.3 \\
\text { All }\end{array}$ & $\begin{array}{c}42.3 \\
\text { All }\end{array}$ & $\begin{array}{l}\text { 1/15 acute } \\
\text { 0/15 late }\end{array}$ \\
\hline $\begin{array}{l}\text { Jhingran et al., } \\
2003 \text { [4] }\end{array}$ & 52 & RE & $\begin{array}{l}\text { IC or IC/IS } \\
+ \text { EBRT }\end{array}$ & 60 & 86 & N.A. & 52 & N.A. \\
\hline $\begin{array}{l}\text { Pötter et al., } \\
2011 \text { [30] }\end{array}$ & 156 & PC & $\begin{array}{l}\text { IC or IC/IS } \\
+ \text { EBRT }\end{array}$ & 36 & 95 & 82 & 68 & $\begin{array}{l}\text { N.A. acute } \\
11 / 143 \text { late }\end{array}$ \\
\hline $\begin{array}{l}\text { Beriwal et al., } \\
2012 \text { [31] }\end{array}$ & 30 & PV or RV & $I S \pm E B R T$ & 24 & 78.8 & N.A. & 70.2 & $\begin{array}{l}0 \text { acute } \\
\text { 2/30 late }\end{array}$ \\
\hline $\begin{array}{l}\text { Dimopoulos } \\
\text { et al., } 2012 \text { [32] }\end{array}$ & 13 & PV & $\begin{array}{l}\text { IC or IC/IS } \\
+ \text { EBRT }\end{array}$ & 36 & 92 & 85 & 85 & N.A. \\
\hline $\begin{array}{l}\text { Manuel et al., } \\
2016 \text { [33] }\end{array}$ & $47^{1}$ & PV or RV & $I S+E B R T$ & 24 & 93 & N.A. & 82 & N.A. \\
\hline $\begin{array}{l}\text { Gebhardt et al., } \\
2018 \text { [34] }\end{array}$ & 60 & PV or RV & $I C+E B R T$ & 48 & 92.6 & 76.1 & 67.2 & $\begin{array}{c}0 \text { acute } \\
2.9 \% \text { late }\end{array}$ \\
\hline Present study & 13 & PV or RV & $\begin{array}{c}\text { IC or IC/IS } \\
\pm \text { EBRT }\end{array}$ & 36 & 92 & 77 & 92 & $\begin{array}{l}\text { 2/13 acute } \\
1 / 13 \text { late }\end{array}$ \\
\hline
\end{tabular}


The success of MCVCs has prompted modifications to intracavitary applicators for treatment of extensive, infiltrating disease with a single applicator [22]. Commercially available applicators that combine vaginal cylinders and interstitial needles to target apical and lateral vaginal disease, include the Syed, MUPIT, Benidorm, Pamplona, Kelowna, and Venezia [23]. In comparison to the MIAMI, the Syed, MUPIT, and Benidorm applicators directly expose the lateral mucosa and/or perineum to the needles, exposing vaginal mucosa to high doses of radiation $[23,24]$. The Pamplona and Kelowna applicators have peripheral interstitial needles, which require their placement through the potentially healthy perineum [25]. The Venezia applicator has needles going through a ring at the apex with a central tandem/needle, allowing for treatment of apical lesions without excessive surface dose and placement of interstitial transperineal needles, but it is limited by its maximal applicator size of $30 \mathrm{~mm}$. The Venezia is also compatible only with Elekta system and cannot be used with Varian afterloader [26]. When comparing the interstitial MIAMI applicator to other studies, we report similar rates of loco-regional control, distant-control, and overall survival, as detailed in Table 2 $[4,27,28,29,30,31,32,33,34]$. Moreover, we have discussed this design with commercial brachytherapy vendors describing its advantages, and they have been received positively, leading to a discussion regarding future applicator design/products.

The interstitial MIAMI applicator has similar advantages as custom 3D printer applicators [35]. These 3D-printed applicators are customized to patient's anatomy and have a protective shell around the needles, with needles extending directly into the vaginal apex to treat apically located lesions. These 3D-printed applicators, however, rely on the availability of a 3D printer and time for customization, are typically not reusable, and there is limited research for the various materials used to design 3D-printed applicators and their resulting dose distributions $[36,37]$.

Limitations of this study include the small, varied cohort as few patients qualified for this specific treatment modality. Furthermore, several patients were followed-up outside institutions after receiving VBT, limiting analysis of long-term results. Despite these limitations, we report acceptable toxicities and rates of local recurrence within the timeframe for follow-up care.

\section{Conclusions}

The modified interstitial MIAMI applicator shows a potential for the treatment of large, apically located vaginal lesions. The device could be used to provide radiation for patients who are not be suitable for perineal interstitial brachytherapy, with added benefits of reduced procedural time, morbidity, use of anesthesia, and need for expertise. This flexible device could be used as a simple, single-channel applicator to a complex, multi-channel applicator with interstitial needles, increasing the number of patients, which could be treated with a single intracavitary device.

\section{Disclosure}

The authors report no conflict of interest.

\section{References}

1. Whitcomb BP. Gynecologic malignancies. Surg Clin North Am 2008; 88: 301-317.

2. Harkenrider MM, Block AM, Alektiar KM et al. American Brachytherapy Task Group Report: Adjuvant vaginal brachytherapy for early-stage endometrial cancer: A comprehensive review. Brachytherapy 2017; 16: 95-108.

3. Chapman $\mathrm{CH}$, Maghsoudi K, Littell RD et al. Salvage highdose-rate brachytherapy and external beam radiotherapy for isolated vaginal recurrences of endometrial cancer with no prior adjuvant therapy. Brachytherapy 2017; 16: 1152-1158.

4. Jhingran A, Burke TW, Eifel PJ. Definitive radiotherapy for patients with isolated vaginal recurrence of endometrial carcinoma after hysterectomy. Int J Radiat Oncol Biol Phys 2003; 56: 1366-1372.

5. Chakrabarti B, Basu-Roy S, Kar SK et al. Comparison of dose volume parameters evaluated using three forward planning - optimization techniques in cervical cancer brachytherapy involving two applicators. J Contemp Brachytherapy 2017; 9: 431-445.

6. Banerjee R, Kamrava M. Brachytherapy in the treatment of cervical cancer: a review. Int J Womens Health 2014; 6: 555-564.

7. Glaser SM, Kim H, Beriwal S. Multichannel vaginal cylinder brachytherapy - impact of tumor thickness and location on dose to organs at risk. Brachytherapy 2015; 14: 913-918.

8. Kim H, Rajagopalan MS, Houser C et al. Dosimetric comparison of multichannel with one single-channel vaginal cylinder for vaginal cancer treatments with high-dose-rate brachytherapy. Brachytherapy 2014; 13: 263-267.

9. Demanes DJ, Rege S, Rodriquez RR et al. The use and advantages of a multichannel vaginal cylinder in high-dose-rate brachytherapy. Int J Radiat Oncol Biol Phys 1999; 44: 211-219.

10. Vargo JA, Kim H, Houser CJ et al. Image-based multichannel vaginal cylinder brachytherapy for vaginal cancer. Brachytherapy 2015; 14: 9-15.

11. Dimopoulos JC, Kirisits C, Petric P et al. The Vienna applicator for combined intracavitary and interstitial brachytherapy of cervical cancer: Clinical feasibility and preliminary results. Int J Radiat Oncol Biol Phys 2006; 66: 83-90.

12. Mendez LC, Paudel M, Wronski M et al. Dosimetric comparison of interstitial brachytherapy with multi-channel vaginal cylinder plans in patients with vaginal tumors. Radiat Oncol 2017; 12: 84 .

13. Fokdal L, Sturdza A, Mazeron R et al. Image guided adaptive brachytherapy with combined intracavitary and interstitial technique improves the therapeutic ratio in locally advanced cervical cancer: Analysis from the retroEMBRACE study. Radiother Oncol 2016; 120: 434-440.

14. Iftimia I, Cirino ET, Mower HW et al. Treatment planning methodology for the Miami Multichannel Applicator following the American Brachytherapy Society recently published guidelines: the Lahey Clinic experience. J Appl Clin Med Phys 2013; 14: 4098

15. Rivard MJ, Coursey BM, DeWerd LA et al. Update of AAPM Task Group No. 43 Report: A revised AAPM protocol for brachytherapy dose calculations. Med Phys 2004; 31: 633-674.

16. American Brachytherapy Society: Physics Corner. https:// www.americanbrachytherapy.org/resources/for-professionals/physics-corner/. (accessed July 1, 2019).

17. Beriwal S, Demanes DJ, Erickson B et al. American Brachytherapy Society consensus guidelines for interstitial brachytherapy for vaginal cancer. Brachytherapy 2012; 11: 68-75. 
18. Viswanathan AN, Erickson BA. Three-dimensional imaging in gynecologic brachytherapy: a survey of the American Brachytherapy Society. Int J Radiat Oncol Biol Phys 2010; 76: 104-109.

19. Harkenrider MM, Block AM, Siddiqui ZA et al. The role of vaginal cuff brachytherapy in endometrial cancer. Gynecol Oncol 2015; 136: 365-372.

20. Rajagopalan MS, Xu KM, Lin J et al. Patterns of care and brachytherapy boost utilization for vaginal cancer in the United States. Pract Radiat Oncol 2015; 5: 56-61.

21. Nielsen AA, Liyanage TA, Leiserowitz GS et al. Optimal perioperative anesthesia management for gynecologic interstitial brachytherapy. J Contemp Brachytherapy 2017; 9: 216-223.

22. Shin SM, Duckworth TL, Cooper BT et al. Use of a flexible inflatable multi-channel applicator for vaginal brachytherapy in the management of gynecologic cancer. Front Oncol 2015; 5: 201.

23. Biltekin FB. Physical and dosimetric properties of the applicators used in cervix cancer brachytherapy: ICRU 89 Recommendation. Turk J Oncol 2019; 34.

24. Martinez A, Cox RS, Edmundson GK. A multiple-site perineal applicator (MUPIT) for treatment of prostatic, anorectal, and gynecologic malignancies. Int J Radiat Oncol Biol Phys 1984; 10: 297-305.

25. Richart J, Carmona-Meseguer V, García-Martínez T et al. Review of strategies for MRI based reconstruction of endocavitary and interstitial applicators in brachytherapy of cervical cancer. Rep Pract Oncol Radiother 2018; 23: 547-561.

26. Morcos M, Sheikh K, Rezaee M et al. Commissioning and loading pattern determination for Elekta's Venezia gynecological applicator for patients with advanced cervical cancer. Brachytherapy 2018; 17: S36.

27. Stock RG, Mychalczak B, Armstrong JG et al. The importance of brachytherapy technique in the management of primary carcinoma of the vagina. Int J Radiat Oncol Biol Phys 1992; 24 : 747-753.

28. Chyle V, Zagars GK, Wheeler JA et al. Definitive radiotherapy for carcinoma of the vagina: Outcome and prognostic factors. Int J Radiat Oncol Biol Phys 1996; 35: 891-905.

29. Nag S, Martínez-Monge R, Copeland LJ et al. Perineal template interstitial brachytherapy salvage for recurrent endometrial adenocarcinoma metastatic to the vagina. Gynecol Oncol 1997; 66: 16-19.

30. Pötter R, Georg P, Dimopoulos JC et al. Clinical outcome of protocol based image (MRI) guided adaptive brachytherapy combined with 3D conformal radiotherapy with or without chemotherapy in patients with locally advanced cervical cancer. Radiother Oncol 2011; 100: 116-123.

31. Beriwal S, Rwigema J-CM, Higgins E et al. Three-dimensional image-based high-dose-rate interstitial brachytherapy for vaginal cancer. Brachytherapy 2012; 11: 176-180.

32. Dimopoulos JC, Schmid MP, Fidarova E et al. Treatment of locally advanced vaginal cancer with radiochemotherapy and magnetic resonance image-guided adaptive brachytherapy: dose-volume parameters and first clinical results. Int J Radiat Oncol Biol Phys 2012; 82: 1880-1888.

33. Manuel MM, Cho LP, Catalano PJ et al. Outcomes with image-based interstitial brachytherapy for vaginal cancer. Radiother Oncol 2016; 120: 486-492.

34. Gebhardt BJ, Vargo JA, Kim H et al. Image-based multichannel vaginal cylinder brachytherapy for the definitive treatment of gynecologic malignancies in the vagina. Gynecol Oncol 2018; 150: 293-299.

35. Laan RC, Nout RA, Dankelman J et al. MRI-driven design of customised 3D printed gynaecological brachytherapy applicators with curved needle channels. 3D Print Med 2019; 5: 8.

36. Logar HBZ, Hudej R, Šegedin B. Development and assessment of 3D-printed individual applicators in gynecological
MRI-guided brachytherapy. J Contemp Brachytherapy 2019; 11: 128-136.

37. Sethi R, Cunha A, Mellis K et al. Clinical applications of custom-made vaginal cylinders constructed using three-dimensional printing technology. J Contemp Brachytherapy 2016; 8: 208-214. 
Appendix A. Full company name and address for drill bit Robert Bosch LLC

38000 Hills Tech Drive

Farmington Hills, MI 48331

USA

Appendix B. Acute and chronic toxicity data. Numerical count of reported acute (less than three months) and chronic (greater than three months) toxicities using the CTCAE 4.0 criteria for the ten patients with collected toxicity data

\begin{tabular}{|c|c|c|c|c|c|c|c|}
\hline $\begin{array}{l}\text { Acute } \\
\text { toxicity }\end{array}$ & Grade 1 & Grade 2 & Grade 3 & $\begin{array}{l}\text { Chronic } \\
\text { toxicity }\end{array}$ & Grade 1 & Grade 2 & Grade 3 \\
\hline Cystitis & 3 & 2 & - & $\begin{array}{l}\text { Lower Gl } \\
\text { hemorrhage }\end{array}$ & - & 2 & - \\
\hline $\begin{array}{l}\text { Dermatitis } \\
\text { radiation }\end{array}$ & - & 2 & - & Fistula & 1 & - & 1 \\
\hline Diarrhea & 5 & 1 & - & Pelvic pain & 3 & 1 & - \\
\hline Fatigue & 5 & 2 & 1 & Proctitis & 1 & 1 & - \\
\hline Nausea & 1 & - & 2 & Telangiectasia & 3 & - & - \\
\hline Pelvic pain & 3 & 2 & - & $\begin{array}{l}\text { Urinary } \\
\text { incontinence }\end{array}$ & - & 2 & - \\
\hline \multirow[t]{3}{*}{ Proctitis } & 3 & 1 & - & $\begin{array}{l}\text { Vaginal } \\
\text { dryness }\end{array}$ & 1 & - & - \\
\hline & & & & $\begin{array}{l}\text { Vaginal } \\
\text { hemorrhage }\end{array}$ & 2 & - & - \\
\hline & & & & $\begin{array}{l}\text { Vaginal } \\
\text { stricture }\end{array}$ & 4 & - & - \\
\hline
\end{tabular}

